\title{
Perindopril-associated pneumonitis
}

\author{
A. Benard*, B. Melloni**, B. Gosselin+, F. Bonnaud**, B. Wallaert*
}

Perindopril-associated pneumonitis. A. Benard, B. Melloni, B. Gosselin, F. Bonnaud, B. Wallaert. (CERS Journals Ltd 1996.

ABSTRACT: We report two cases of perindopril-associated pneumonitis with typical drug-induced clinical features. In the first case, biopsies showed granulomatous sarcoid-like lesions; in the second, bronchial wall eosinophil infiltration was reported with increased blood eosinophil count.

In these two cases, improvement was obtained by withdrawal of the drug and was completed with steroids. All other causes were ruled out. Angiotensin-converting enzyme inhibitor (ACEI)-induced pneumonitis is still rare but has to be recognized as a real side-effect.

Eur Respir J., 1996, 9, 1314-1316.
*Service de Pneumologie-Immunoallergologie, et +Service d'Anatomie Pathologique, Hôpital Calmette, CHU, Lille, France. **Service de Pathologie Respiratoire et d'Allergologie, Hôpital de Cluzeau, CHU, Limoges, France.

Correspondence: B. Wallaert, Service de Pneumologie et Immunoallergologie, Hôpital A. Calmette, Bd duProfesseur Jules Leclerc, 59037 Lille Cedex, France

Keywords: Angiotensin-converting enzyme inhibitors, drug-induced pneumonitis

Received: January 231995

Accepted after revision December 151995
Perindopril is an angiotensin-converting-enzyme inhibitor (ACEI). It is a prodrug with a 27 hour half-life metabolite (Perindoprilate). ACEI are associated with many respiratory side-effects [1]; the most frequently reported being dry cough with or without bronchial hyperreactivity [2]. Two case reports have suggested the possibility of the uncovering of an asthmatic tendency [3] and development of persistent late onset asthma following treatment with captopril. ACEI seems to be incriminated in the genesis and metabolism of bronchomotor mediators [4]. In a recent paper, 36 cases of ACEIinduced life-threatening angioedema were reported between 1984 and 1991 and, for patients with recurring episodes, hereditory factors were considered [5]. Pneumonitis is not a frequent side-effect: we report two cases of perindopril-associated pneumonitis with similar clinical features and different anatomical aspects on microscopic examination.

\section{Case 1}

A 60 year old man was admitted to hospital in May 1991 with dyspnoea, fever and sweats. He had lost $6 \mathrm{~kg}$ in weight within 6 weeks. He was a smoker, with no professional exposure, and had been treated with captopril $50 \mathrm{mg}$ for high blood pressure from 1989 to January 1991. Captopril had been discontinued and another ACEI, perindopril $4 \mathrm{mg}$, introduced. His treatment was completed with benfluorex, endotelon, diosmine since 1991. He had never had any respiratory symptoms. Physical examination revealed bilateral crackles with a right predominance.

Chest radiographic film showed infiltrates in both upper lung fields. Computed tomography revealed peripheral lesions associating reticulonodular infiltrates with groundglass pattern, and alveolar infiltration on the middle right field without lymph node enlargment (fig. 1). Blood tests showed increased inflammatory markers. Serological tests were negative and there was no immunological abnormality. Functional tests showed a restrictive ventilatory defect, and hypoxaemia (table 1), without oxygen desaturation on exertion. Bronchoalveolar lavage (BAL) cell analysis disclosed 140 cells $\cdot \mathrm{mm}^{-3}$ with $83 \%$ macrophages (normal range $84 \pm 7 \%$ ), $12 \%$ lymphocytes (normal range $15 \pm 3 \%$ ), and $5 \%$ neutrophils (normal $<2 \%$ ) [6]. Bronchial and transbronchial biopsies revealed chronic inflammatory and fibrous lesions around and in the bronchial walls.

Antibiotic therapy was initiated successively with ampicillin, amoxycillin-clavulanate, cephalosporin and macrolide, without any improvement. Perindopril was

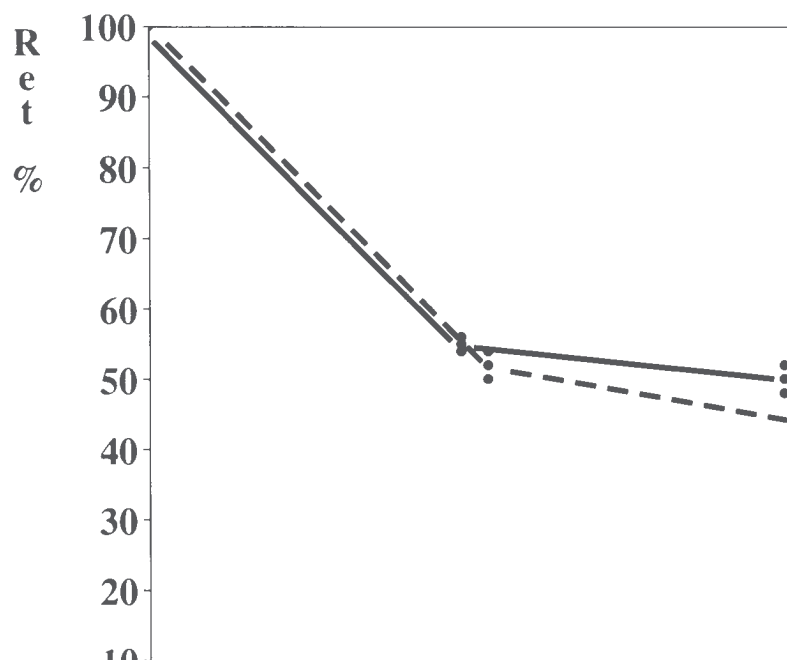

Fig. 1. - High resolution computed tomography (Case 1), showing bilateral alveolar infiltrates, predominant in the right lower and upper lobes. 
Table 1. - Sequential evaluation of pulmonary function tests

\begin{tabular}{lcccccr}
\hline & \multicolumn{2}{c}{$\mathrm{FVC}$} & \multicolumn{2}{c}{$\mathrm{FEV} 1$} & \multicolumn{2}{c}{$\mathrm{Pa}_{\mathrm{a}} \mathrm{O}_{2}$} \\
& $\mathrm{~L} \%$ pred & $\mathrm{L} \%$ pred & $\mathrm{mmHg}$ & $\mathrm{kPa}$ \\
\hline Case 1 & & & & & & \\
Day 1 & 2.25 & 58 & 1.68 & 55 & 68 & 9.1 \\
1 month later & 2.72 & 68 & 1.73 & 55 & 60 & 8.0 \\
3 months later & 2.93 & 80 & 2.16 & 68 & 72 & 9.6 \\
1 year later & 3.33 & 86 & & & 83 & 11.1 \\
Case 2 & & & & & & \\
Day 1 & 2.17 & 59 & 1.57 & 58 & 62 & 8.3 \\
6 months later & 3.23 & 88 & 1.57 & 58 & 80 & 10.7 \\
\hline
\end{tabular}

FVC: forced vital capacity; FEV1: forced expiratory volume in one second; \% pred: percentage of predicted normal value; $\mathrm{P}_{\mathrm{a}, \mathrm{O}_{2}}$ : arterial oxygen tension.

discontinued on July 3, 1991, with significant clinical and arterial blood gases improvement (table 1). Six weeks after withdrawal of the drug, chest radiography and computed tomography were improved. Abnormalities persisted in the left lower lobe. Transbronchial biopsies were performed again, showing two granulomatous sarcoidlike lesions composed of epithelioid and giant cells. Open-lung biopsy was performed because of persistent hypoxaemia and showed focal collapsed alveoli with lymphocytic and macrophagic alveolitis. Interstitial fibrosis was noted, with nodular confluent elements comprised of epithelioid and giant cells. Circular fibrosis and lymphocytes were observed at the periphery. Necrosis was not present.

Perindopril-induced pneumonitis seemed likely and corticosteroid therapy, $0.5 \mathrm{mg} \cdot \mathrm{kg}^{-1} \cdot \mathrm{day}^{-1}$, was initiated. Four months later, the patient's weight had improved and normal computed tomography was noted. Improvement of pulmonary function was slower (table 1). Corticosteroid therapy was reduced and stopped. Three years later, the patient is still clinically and radiologically well.

\section{Case 2}

A 73 years old man was admitted to hospital in April 1992 with $39^{\circ} \mathrm{C}$ fever, dry cough, and dyspnoea. He had been working as a farmer but no professional exposure was noted when he became ill. He had been treated for 6 months with perindopril for high blood pressure. He had stopped smoking 20 yrs previously. No infectious syndrome was noted during the weeks before consultation. On admission, physical examination revealed anorexia ( $5 \mathrm{~kg}$ weight loss), $38.5^{\circ} \mathrm{C}$ fever, peripheral cyanosis, severe dyspnoea, and diffuse crackles with a right predominance. His blood pressure was $140 / 90 \mathrm{mmHg}$ and he had no signs of cardiac failure.

Initial chest radiographic film disclosed a bilateral interstitial pattern, with alveolar infiltration. Computed tomography showed infiltrates with a ground-glass and mixed reticular pattern, with many alveolar infiltrates and focal pleural thickening (fig. 2). Sedimentation rate was 110 $\mathrm{mm} \cdot \mathrm{h}^{-1}$, white blood cell (WBC) count was 15,700 cells $\cdot \mathrm{mm}^{-3}\left(15.7\right.$ cells $\left.\times 10^{9} \cdot \mathrm{L}^{-1}\right)$ with 940 eosinophils $\cdot \mathrm{mm}^{-3}$ $\left(0.94\right.$ cells $\left.\times 10^{9} \cdot \mathrm{L}^{-1}\right)$. Arterial blood gas revealed isolated hypoxaemia (table 1). Functional tests showed marked restriction with decreased transfer factor of the lungs for

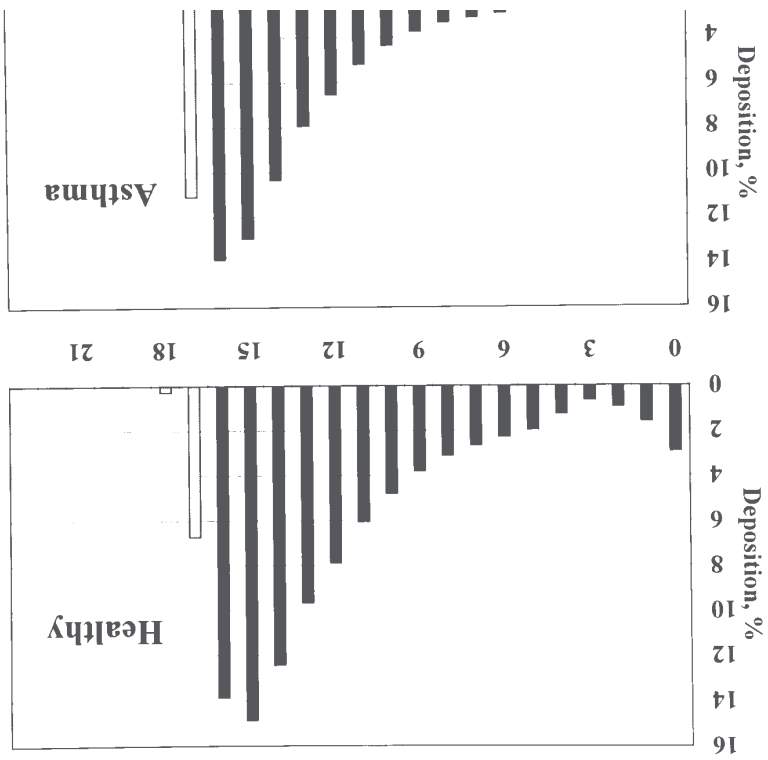

Fig. 2. - Initial computed tomography (Case 2) showing a reticular pattern, with alveolar infiltrates, ground-glass and focal pleural thickening.

carbon monoxide (TL,CO). Fibreoptic endoscopy was normal and BAL cell analysis revealed 250,000 cells $\cdot \mathrm{mm}^{-3}$, with $77 \%$ macrophages, $16 \%$ lymphocytes, $2 \%$ neutrophils and 5\% eosinophils. Transbronchial biopsies showed bronchial wall eosinophil infiltration. There was no alveolar damage or granuloma. Blood cultures and blood, sputum and urine samples for pathogen research were negative. Serological tests for extrinsic alveolitis; Mycoplasma pneumoniae, Legionella and parasites were negative. Complement, immunological tests, and serum ACE were normal.

This report was consistent with drug-induced pneumonitis and perindopril was withdrawn. Twelve days later, corticosteroid therapy, $1 \mathrm{mg} \cdot \mathrm{kg}^{-1}$, was initiated because improvement was too slight, and was then progressively tapered. Clinical improvement was marked, cough and fever decreased, eosinophil count and inflammatory markers progressively decreased. Chest radiographic improvement was slower. Lung function tests, blood gas and blood cell count returned to normal.

Rechallenge was not performed but, 7 months later, the patient took a perindopril tablet; after $3 \mathrm{~h}$, fever and cough with dyspnoea appeared. He was readmitted and physical examination revealed diffuse crackles. The chest radiographic film showed bilateral infiltrates. WBC count was 18,600 cells $\cdot \mathrm{mm}^{-3}\left(18.6\right.$ cells $\left.\times 10^{9} \cdot \mathrm{L}^{-1}\right)$ with 744 eosinophils $\cdot \mathrm{mm}^{-3}\left(0.74\right.$ cells $\left.\times 10^{9} \cdot \mathrm{L}^{-1}\right)$. Improvement was rapidly obtained with a mild dose of corticosteroids. The follow-up is still clinically, functionally and radiologically stable.

\section{Discussion}

ACEI-related pneumonitis is rare. This class is not mentioned in classical features of drug-induced pneumonitis [7]. KIDNEY et al. [8] reported a case of captoprilassociated lymphocytic alveolitis, with clinical and radiological improvement 1 week after withdrawal of the drug. BAL and lung function tests normalized after 6 
months. Biopsies and rechallenge were not performed. Schatz et al. [9] described a case of captopril-induced lung disease related to a hypersensitivity mechanism with immune complex and hypereosinophilia. All other causes of eosinophilia were ruled out. Transbronchial biopsies showed an eosinophilic infiltrate with fibrous areas. There was no drug rechallenge.

In our reports, the only change in treatment was the withdrawal of ACEI. Infectious diseases were eliminated. Patients were not exposed to inhaled antigen. Histological findings were not suggestive of bronchiolitis obliterans organizing pneumonitis. Radiological aspects were nonspecific. In the first case, pathohistological data revealing granulomatous sarcoid-like lesions suggested drug-induced pneumonitis but sarcoidosis or other granulomatous diseases could not be ruled out: indeed, normal lymphocytosis in BAL, a normal serum ACE value, clinical and radiological improvement beginning before corticosteroid therapy was initiated were not consistent with sarcoidosis. In the second case, bronchial wall eosinophilic infiltrate and blood eosinophilia were highly suggestive of a drug-induced disease, and rechallenge was clearly decisive for the diagnosis.

In these two cases, perindopril-induced pneumonitis seems likely. The rapidly favourable outcome without any specific treatment eliminated all other causes. Chronology, the main criterion for consensus [10] is compatible with perindopril-associated disease. In addition, in the second case, rechallenge was clearly decisive for the diagnosis.

\section{References}

1. Lunde H, Hedner T, Samuelson O, et al. Dyspnea, asthma and bronchospasm in relation to treatment with angiotensin-converting enzyme inhibitors. BMJ 1994; 308: $18-21$.

2. Bucknall CE, Neilly JB, Carter R, Stevenson RD, Semple PF. Bronchial hyperreactivity in patients who cough after receiving angiotensin-converting enzyme inhibitors. $B M J$ 1988; 296: 86-88.

3. Lipworth BJ, McMurray JJ, Clarck RA, Struthers AD. Development of persistent late onset asthma following treatment with captopril. Eur Respir J 1989; 2: 586-588.

4. Popa V. Captopril-related (and induced?) asthma. Am Rev Respir Dis 1987; 136: 999-1000.

5. Thompson T, Frable MA. Drug-induced, life-threatening angioedema revisited. Laryngoscope 1993; 103: 10-12.

6. Report of the European Society of Pneumology Task Group on BAL. Technical recommendations and guidelines for bronchoalveolar lavage. Eur Respir J 1989; 2: 561-585.

7. Cooper JAD, White DA, Matthay RA. Drug-induced pulmonary disease. Part 2. Noncytotoxic drugs. Am Rev Respir Dis 1986; 133: 488-505.

8. Kidney JC, O'Halloran DJ, Fitzgerald MX. Captopril and lymphocytic alveolitis. BMJ 1989; 299: 981.

9. Schatz JC, O'Halloran DJ, Fitzgerald MX. Captoprilinduced hypersensitivity lung disease. Chest 1989; 95 : 685-687.

10. Fournier M, Camus P, Benichou C, et al. Pneumopathies interstitielles: critères d'imputation à un médicament. Presse Méd 1989; 18: 1336-1338. 